\title{
Review
}

\section{The nutrient supply of pathogenic fungi; a fertile field for study}

\author{
PETER S. SOLOMON, KAR-CHUN TAN AND RICHARD P. OLIVER* \\ The Australian Centre for Necrotrophic Fungal Pathogens, SABC, DSE, Murdoch University, Perth 6150, Western Australia, Australia
}

\section{SUMMARY}

Phytopathogenic fungi must feed on their hosts to propagate and cause disease. Their ability to access the rich nutrient supply offered by living plants is one of the most obvious properties that distinguish pathogens from saprophytes. Successful invasion by pathogens depends as much on their ability to utilize the available nutrient sources offered by plants as on their ability to penetrate plants and evade defensive mechanisms. Here, we review current knowledge on the nature of the nutrient supplies utilized by pathogens during infection.

The available evidence is rudimentary in most cases. There is much evidence to suggest that fungal metabolism can be divided into at least two phases. The first is based on lipolysis and occurs during germination and penetration of the host. The second phase uses glycolysis and predominates during the invasion of host tissue. We also propose, mainly on theoretical grounds, that a third phase of nutrition occurs late in infection during which new spores are produced.

Contrary to early assumptions, the nitrogen sources available to some pathogens appear to be abundant. The idea that nitrogen starvation is a cue that controls fungal gene expression during infection may need to be reassessed. Very little is known about the micronutrient $(\mathrm{Fe}, \mathrm{S}, \mathrm{P})$ or vitamin supply. The knowledge gained from this research may enable the design of new antifungal strategies targeting potential weaknesses in fungal metabolism and will also impact on agronomic practices.

\section{INTRODUCTION}

Pathogenicity can be broadly defined as the ability of a pathogen to interfere with the host plant, thus resulting in a disease (Holliday, 1992). It depends on a range of properties that distinguish pathogens from saprobes. Properties such as the production of toxins, cell wall degrading enzymes, host penetration, signal transduction and avirulence genes are well recognized as

*Correspondence: E-mail: roliver@central.murdoch.edu.au pathogenicity factors (reviewed in Idnurm and Howlett, 2001). The ability of a fungus to feed on a plant is no less important, but has been relatively ignored. The purpose of this review is to highlight studies on in planta nutrition that suggests that the nutrient supply of fungal pathogens may be as important as the above factors during pathogenesis.

\section{EFFECT OF THE EXTERNAL ENVIRONMENT OF THE PLANT ON DISEASE DEVELOPMENT}

\section{The effect of fertilizer application on pathogenicity}

The interaction of fungal disease and fertilizers is of great practical interest and there have been numerous studies into the interaction of (in particular) nitrogenous fertilizer and disease. Application of nitrogen above the recommended rate has often been shown to significantly increase disease incidence and lesion area. This applies to both necrotrophic (Magnaporthe grisea, Long et al., 2000) and biotrophic pathogens (Blumeria graminis f. sp. tritici; and tomato mildew Oidium lycopersicum; Hoffland et al., 2000; Jensen and Munk, 1997).

The nature of the nitrogen also has an effect. Huber and Watson's (1974) review noted that nitrate consistently increased and ammonium decreased the incidence of (hemi)-biotrophs (mildew, Colletotrichum and rust) whereas nitrate decreased and ammonium increased the incidence of the necrotrophs Cochliobolus, Magnaporthe and Botrytis.

Sub-optimal nitrogen can also lead to more disease. In the grey mould pathogen Botrytis cinerea, the formation of primary lesion on tomatoes was more frequent with low nitrogen levels (Hoffland et al., 1999). These plants have a high physiological carbon/nitrogen ratio and a large amount of soluble carbohydrates in tissue (Hoffland et al., 1999), indicating that the growth of the pathogen was dependent on high soluble carbohydrate levels.

The hypotheses being tested in the above studies can be redefined as follows;

(A) An insufficiency of fertilizer leads to susceptibility by weakening a plant and promoting invasion and disease.

(B) Superabundant fertilizer leads to hyper-susceptibility by either: 
1 providing excess nutrient that is directly available to support the growth of pathogens,

2 promoting the growth of ill-defended plant tissue, or

3 diverting metabolic resources into the assimilation of the nutrient.

Studies that might distinguish these possibilities have given conflicting results. Matsuyama and Dimond (1973) showed that the application of nitrogenous fertilizers to rice led to a reduction in the activities of enzymes in the phenylpropanoid pathway and the production of lignin, suggesting that fertilizers compromised the intensity of secondary plant defences. This is consistent with hypothesis B3. The positive effect of ammonium on necrotrophs is consistent with hypothesis B1, whereas the positive effect of low nitrogen on Botrytis is consistent with $\mathrm{A}$.

Clearly more work is needed in this area and it is, of course, likely that different fungi will respond in different ways to the application of fertiliser. It is important that future studies combine measurements of fungal growth and symptom production with plant biomass and in planta nutrient levels. The use of fungal strains carrying reporter gene constructs linked to nutrient-responsive promoters (for example Bowyer et al., 2000) is a major technical advance that is likely to elucidate this problem.

\section{The effect of mycorrhizal symbiosis on pathogenicity}

Like fertilization application, arbuscular mycorrhizae (AM) affect pathogenicity. It has been commonly reported that plants inoculated with AM show increased leaf pathogen loads. Dehne (1982) suggested that this increased pathogenicity is probably due to enhanced nutrition and plant growth of mycorrhizal plants. Gernns et al. (2001) suggested that improved management of the plant storage pools provided by the AM symbiosis compensates for the deleterious effect of mildew infection on grain yield in barley.

\section{The effect of $\mathrm{CO}_{2}$ levels on plant-pathogen interactions}

Studies on plant responses to elevated $\mathrm{CO}_{2}$ levels have revealed a clear link to pathogen resistance. When barley was grown in elevated $\mathrm{CO}_{2}$ concentrations, photosynthesis was higher and inoculation with powdery mildew spores produced fewer colonies. However established $B$. graminis colonies grew at a greater rate at elevated atmospheric $\mathrm{CO}_{2}$ (Hibberd et al., 1996a,b). The authors concluded that plants in grown in elevated $\mathrm{CO}_{2}$ have enhanced defensive capabilities, presumably because of the faster deployment of defensive secondary metabolites and cellwall strengthening. Once penetrated however, the pathogen was able to grow faster, suggesting that fungal substrate supply was the limiting factor.

\section{IN VITRO NUTRITIONAL REQUIREMENTS}

Many non-obligate fungal pathogens can be grown axenically in minimal media consisting of only a simple carbohydrate, nitrogen (as nitrate), phosphate, and trace metals (see, for example Lau and Hamer, 1996; Newton and Caten, 1988). Phytopathogenic fungi are often capable of using two-carbon compounds such as acetate and ethanol (Bowyer et al., 2000), sugar alcohols (Noeldner et al., 1994), fatty acids (Bowyer et al., 2000; Segers et al., 2001), proteins/amino acids (Jennings and Lysek, 1996; Murphy and Walton, 1996), and plant cell wall materials (Jennings and Lysek, 1996; Lehtinen, 1993). Phytopathogenic fungi can also use many nitrogen sources such as ammonium, nitrate, amino acids and proteins. The non-protein amino acid $\gamma$-aminobutyric acid (GABA) is a very efficiently used $\mathrm{N}$ source in vitro (Solomon and Oliver, 2002). There is therefore good evidence that many phytopathogens can metabolize all the major substrates likely to be available to them during growth in planta.

Obligate pathogens cannot, by definition, be grown in culture. Unlike fastidious bacteria, the provision of complex nutrient sources has rarely been shown to enable the growth of such fungi. Instead, it appears that the regulation of nutrient assimilation transporters and enzymes is dependent on factors or signals produced by the plant. Haustoria appear to be the main site of nutrient uptake in obligate pathogens. In vitro conditions which induce the appropriate expression of the genes required for haustorial function have rarely been discovered (Hahn and Mendgen, 1997; Thomas et al., 2001, 2002).

\section{METHODOLOGIES TO STUDY IN PLANTA NUTRITION}

\section{Expression of metabolism-related genes in planta}

Expressed sequence tag (EST) studies of pathogens would seem to have great potential in identifying fungal nutritional pathways expressed during infection. At first sight, the identification of pathogen genes involved in a given metabolic pathway would appear to indicate that the pathway operates during infection. However, for this conclusion to be drawn, several criteria need to be addressed. Firstly, it must be shown that the gene is expressed at an appreciable level in planta. Secondly, the function of the gene product must be ascertained; some form of functional characterization is needed to confirm the properties of a gene product. Thirdly, if the encoded enzyme catalyses a reversible reaction, it is necessary to determine whether its metabolite is being synthesized or consumed.

Isolating fungal genes from infected tissue is often problematic. Differential screening was used to identify plant-induced fungal genes in the rice blast system (Talbot et al., 1993), leading to the identification and characterization of a hydrophobin. It is 
possible in some special cases to isolate pure fungal tissue from within plants (Hahn and Mendgen, 1997). Haustoria of Uromyces fabae can be purified and used as a source of mRNA for library construction. This approach has given a direct window into fungal gene expression with many surprising results (see below).

A number of groups have isolated genes from in vitro grown tissue and subsequently analysed their expression in planta (Coleman et al., 1997; Oliver et al., 2000; Stephenson et al., 2000). The conditions under which the fungus is grown in vitro can be altered in an attempt to mimic in planta conditions. The use of starvation as a potential mimic of in planta expression was suggested by the observation that the avirulence gene avr9 was induced in vitro only by nitrogen limitation (van den Ackerveken et al., 1994). Another approach also uses pure fungal material but utilizes cells that are undergoing infection-specific morphological changes, such as appressorial maturation (Hwang and Kolattukudy, 1995; Thomas et al., 2001, 2002). These studies are based on the assumption that the genes expressed during infection-specific morphological changes would also be expressed during appressorial infection on plants.

\section{Real-time monitoring of gene expression during infection}

An alternative way of assessing the role of a gene product in fungal nutrition expression is to generate promoter-reporter fusions and to follow expression of the reporter during the infection cycle. This approach, using confocal microscopy and GFPexpressing (green fluorescent protein) constructs, is well suited to uncovering the spatial and temporal details of gene regulation in planta. Several caveats also apply to this technique. Since gene expression is measured qualitatively, it can only provide a rough indication of the amount of the enzyme and of the flux through the pathway. GFP is a relatively slowly synthesized and long-lived reporter molecule (Cubitt et al., 1995). Therefore, it is best suited to measuring slow (several hours to days) changes in gene expression rates. Nonetheless, this method has thrown new light on the glyoxylate shunt in Tapesia yallundae (Bowyer et al., 2000) and could be used to study many other pathways.

\section{Auxotrophic mutational analysis}

In contrast to the many caveats associated with genomic methods, the generation of mutants impaired in their ability to utilize a particular nutrient is accepted as a powerful way of studying pathogen nutrition. Traditionally, mutants were selected after treatment with (chemical or radiation) mutagens and screened for auxotrophy. Ideally, genetic analysis would have indicated that a single mutation was present and feeding studies determined the affected enzyme. More recently, mutations have been generated using site-specific gene disruption (reviewed in
Idnurm and Howlett, 2001). These studies have enhanced our understanding of all aspects of fungal nutrition.

\section{Measurement of nutrient concentration fluxes during infection}

A direct way of studying fungal nutrition is to measure the changes in the concentration of potential nutrient sources in the plant during infection. This approach is best suited to pathogens that are restricted to the apoplast; the prime example is Cladosporium fulvum. Apoplastic washing fluids can be recovered and their contents measured. The interpretation of these results is not straightforward, as both the plant and the fungus might be contributing to both the synthesis and consumption of each compound. This method has been used to study both carbohydrate and nitrogen metabolic profiles (Joosten et al., 1990; Solomon and Oliver, 2001). Microscopical stains for lipid and glycogen can give valuable spatial, if qualitative, information on the presence and accumulation of nutrient sources (Thines et al., 2000).

\section{IN PLANTA NUTRITIONAL STUDIES}

\section{Carbon}

Carbon catabolism is the source of the energy used by the fungus during infection. Prior to penetration, the fungus must rely on stored sources of carbon. These are likely to include glycogen, trehalose, sugar alcohols and lipids (Jennings and Lysek, 1996; Thines et al., 2000; Weber et al., 2001). Genomic studies using ESTs and SAGE (serial analysis of gene expression) have indicated that the barley powdery mildew pathogen expresses genes required for glycogen breakdown, glycolysis, lipolysis, $\beta$-oxidation and the TCA cycle (Thomas et al., 2001, 2002). Temporal analysis suggests that lipid catabolism persists throughout the germination and penetration phases but that glycolysis may decline in relative importance as the appressorium matures. Expression of the glyoxylate shunt enzyme isocitrate lyase (ICL) is characteristic of lipid metabolism. Using a GFP fusion, Bowyer et al. (2000) showed that the expression of ICL in $T$. yalundae was highest in spores and hyphae prior to penetration into the host, suggesting that lipids were being consumed during penetration. Histochemical (Thines et al., 2000; Weber et al., 2001) studies on M. grisea indicated that the breakdown of lipid is the main source of the glycerol required to generate turgor pressure in the appressoria (de Jong et al., 1997). The generation of targeted mutations has also implicated lipid metabolism in the penetration phase. Kimura et al. (2001) created mutants deficient in ClaPEX6 in the cucumber anthracnose pathogen Colletotrichum lagenarium. The product of ClaPEX6 is required for peroxisome biogenesis where enzymes for $\beta$-oxidation of fatty acids reside. Mutants of clapex 6 
failed to grow in a medium supplied with fatty acids as carbon and lacked the ability to penetrate the host.

After penetration, the presumably rich resources within the plant become available. As C. fulvum only grows within the apoplast of the tomato leaf, it is possible to extract the intercellular fluid and determine which nutrients are present and presumably available to the fungus. Joosten et al. (1990) examined the sugar composition in the leaf apoplast of tomato infected with C. fulvum over a 14-day infection period. Sucrose levels accumulated during the early stages of infection but declined later. Glucose and fructose levels increased as sucrose declined. The levels of glucose and fructose fell in the later stages of infection and were replaced by mannitol. These results suggest that plant and/or fungal invertases cleave photosynthetic sucrose into fructose and glucose, which are in turn converted to mannitol by the fungus (Noeldner et al., 1994). The role of mannitol is not clear but may include defence against reactive oxygen species (Jennings et al., 1998). It was surprising to note that the total sugar concentration remained high until late in the infection cycle (Joosten et al., 1990). Fungal demand for nutrient increases as fungal biomass accumulates. This implies that there must be a net transfer of carbohydrate from plant source cells into the apoplast that is more than enough to supply the fungus, at least until close to the end of the infection cycle. A high effective sugar concentration within the leaf is also indicated in T. yallundae-infected wheat. GFP fluorescence of ICL declined rapidly after penetration, indicating the availability of sugars within the host. (Bowyer et al., 2000). Direct measurements of powdery mildew-infected barley leaves indicate high levels of fructose, glucose and sucrose (Scholes et al., 1994). Genomic studies have also confirmed that sugars act as the predominant carbon source during infection (Voegele et al., 2001). A hexose transporter gene, HXT1 from U. fabae, is specifically expressed in the haustorium during infection. An elegant study using asymmetrically labelled sucrose has further indicated that wheat mildew haustoria take up glucose, but not sucrose (Sutton et al., 1999).

A large number of depolymerases have been isolated from pathogenic fungi. These include cell wall degrading enzymes and proteases. It has been difficult to establish a role in pathogenicity for many of these enzymes because of genetic redundancy. It is furthermore unclear whether these enzymes have specific roles in penetration or nutrition for the same reason.

Deletion of a gene encoding ccSNF1, a transcription factor from Cochliobolus carbonum, abolished pathogenicity. ccSNF1 is an orthologue of a yeast gene that controls the expression of carbon catabolite repressed genes. Amongst the genes controlled in $C$. carbonum is a suite of cell wall degrading enzymes. The mutants have a reduced penetration efficiency and pathogenicity on maize but also have impaired ability to catabolize arabinose, xylose, xylan and cellulose, the main constituent of the monocot cell wall. Thus, whilst the primary role of the genes controlled by
ccSNFI is to penetrate the leaf, a role in nutrition is not ruled out (Tonukari et al., 2000).

What emerges from these studies, from different pathogens and using different techniques, is a paradigm that lipids are the primary sources of energy that are used during germination and penetration. Lipids also appear to provide the materials that are used to generate the osmotic pressure for penetration. Carbohydrates (and proteins) are used sparingly at this early stage. After penetration, sugars are available and become the main energy source, whilst any further lipolysis is inhibited.

\section{Nitrogen}

All nitrogen for fungal growth is derived from plant sources. These sources could include nitrate, ammonia, amino acids and other small molecules and proteins. Genomic studies of barley powdery mildew showed that many of the genes expressed during germination and appressorial formation encode enzymes with putative roles in proteolysis and amino acid recycling (Thomas et al., 2001, 2002). Thus, some of the nitrogen for early development may well be derived from stored proteins.

The discovery that the $C$. fulvum avirulence gene Avr 9 was only expressed in vitro under nitrogen-limiting conditions suggested that the fungus is starved for nitrogen during growth in planta (Coleman et al., 1997; van den Ackerveken et al., 1994). Indeed, it has been suggested that nitrogen starvation is a cue for symptom development (Snoeijers et al., 2000; Talbot et al., 1997). To address this issue directly, Solomon and Oliver (2001) exploited the $C$. fulvum-tomato system to measure the nitrogenous content of the apoplast during infection. The fluids contained a remarkable diversity of compounds and the total concentration of nitrogen was much higher than expected. Only two of the 20 protein amino acids (Cys and Trp) were undetectable. Evidently these must be synthesized by the fungus during growth. A second group (Met, Arg, His and Pro) were present at very low levels, suggesting that they would also need to be synthesized. The suggestion that the fungus must synthesize Met was supported by studies showing that the biosynthetic gene Met6 was expressed by C. fulvum during infection (Solomon et al., 2000). Furthermore, a M. grisea methionine auxotroph (Balhadere et al., 1999) as well as a Fusarium oxysporum arginine auxotroph (Namiki et al., 2001) were non-pathogenic. We can conclude that synthesis of Met, Arg and probably Trp, Cys, His and Pro, are likely to be general features of pathogenesis. Indeed, commercially successful fungicides such as cyprodanil and pyrimethanil are now believed to target Met biosynthesis (Hewitt, 1998). Other amino acids, notably Ala, Asp, GABA, Glu, Gly and Ser as well as nitrate were present at $\mathrm{mm}$ concentrations in the C. fulvum apoplast. These concentrations would be sufficient to support growth in vitro and can account for the nitrogen used by the fungus during the early and middle 
stages of infection. The levels are sufficient to repress Avr9 expression in C. fulvum in vitro (van den Ackerveken et al., 1994). This suggests that signals other than low nitrogen concentration induce the expression of pathogenicity genes such as Avr9. It will be interesting to determine the nature of the inducing conditions.

The most surprising finding was that the concentration of most amino acids actually increased during infection. One might expect a pathogenic fungus to drain nutrient from a plant. These results therefore suggest that the fungus somehow manipulates plant metabolism to maintain and even increase the apoplastic concentration of nitrogen compounds. This is particularly striking in the case of GABA, a non-protein amino acid which in vitro acts as amongst the most efficient nitrogen sources for the fungus. Furthermore, fungal GAT1, a homologue of GABA transaminase and the tomato glutamate decarboxylase gene are up-regulated during infection, strongly suggesting that the plant is synthesizing and the fungus is catabolizing GABA (Solomon and Oliver, 2002).

It appears that $C$. fulvum's nitrogen requirements are at least partially met by the uptake of amino acids from the apoplast. The rust $U$. fabae expresses amino acid transporters in haustoria, that take up histidine and lysine (Hahn et al., 1997; Mendgen et al., 2000) suggesting a direct uptake from the extra-haustorial space.

Nitrate was present in mu concentrations in the apoplast of $C$. fulvum. Nitrate non-utilizing mutants have been found to be fully pathogenic in C. fulvum, M. grisea and Stagonospora nodorum (Cutler et al., 1998; Lau and Hamer, 1996; Talbot, 1990) suggesting that the fungi do not access nitrate stores during infection. Nitrate assimilation is highly energy-requiring and subject to repression by reduced nitrogen sources. It is likely that amino acids and other reduced nitrogen sources are used in preference to nitrate and these appear to be available.

\section{Vitamins}

Thiamine pyrophosphate (TPP) is used as a co-enzyme in pyruvate dehydrogenase, $\alpha$-ketoglutarate dehydrogenase and transketolase. These are all enzymes associated with carbohydrate utilization. Two of the 31 genes identified as being expressed in haustoria in U. fabae (Hahn and Mendgen, 1997) are involved in TPP synthesis. Sohn et al. (2000) showed that both genes were abundantly and specifically expressed in haustoria. This observation indicates that the fungus must devote considerable resources to the synthesis of this coenzyme.

A pyrimidine auxotroph was selected in $C$. fulvum by selection for 5-fluoroacetate resistance. Complementation with a Ura3 gene confirmed the site of the mutation. The mutant was nonpathogenic whereas pathogenicity was restored in the complemented mutant. This suggests that fungi must synthesize all the pyrimidine from simple precursors during infection (Marmeisse et al., 1993).

Polyamines are a group of positively charged molecules essential for normal cellular functions such as growth and replication (Walters, 2000). Plants subjected to stresses, such as infection, accumulate polyamines. An enzyme crucial to the biosynthesis of polyamines is ornithine decarboxylase. This enzyme catalyses the conversion of ornithine to putrescine and is present in both plants and fungi. Bailey et al. (2000) disrupted the ornithine decarboxylase gene of the wheat blotch pathogen Stagonospora nodorum. As a result, polyamine auxotrophic mutants could only grow if putrescine was supplemented. Furthermore, the authors demonstrated that $O D C$ negative mutants were less pathogenic on wheat, indicating that the fungus cannot utilize polyamines from the host. In contrast, deleting the same gene in Tapesia yallundae did not affect pathogenicity, although infection plaque formation was impaired (Mueller et al., 2001). Clearly, the requirement for polyamines varies.

\section{Sulphur}

Arylsulphatase is synthesized in response to sulphur starvation to increase internal sulphate availability by degrading sulphurcontaining compounds such as tyrosine-0-sulphate. The expression of this enzyme is repressible when sulphur becomes abundant (Marzluf, 1997). The expression of an arylsulphatase gene, cgars, from Colletotrichum gloeosporioides f. sp. malvae was monitored by RT-PCR during infection on round-leaves mallow (Goodwin et al., 2000). The expression of cgars was highest during penetration but gradually declined during growth in planta. This suggests that the pathogen was sulphate-starved during the early stages of infection.

\section{Iron}

Iron acquisition is an important pathogenicity factor in the bacterial and fungal pathogenesis of animals. It was surprising that mutants of Ustilago maydis, which lacked a siderophore gene, retained their pathogenicity (Mei et al., 1993). Clearly the fungus must have other means of acquiring iron that still need to be elucidated.

\section{CONCLUSIONS}

The above review summarizes our current level of knowledge on the relationship between fungal phytopathogenicity and the nutrition provided by the infected host. Given the key role that fungal nutrition must play in phytopathogenicity, surprisingly little is known, in particular, about micronutrient levels. From the evidence gathered above, a model describing the nutrient availability for phytopathogenic fungi during the development of a 


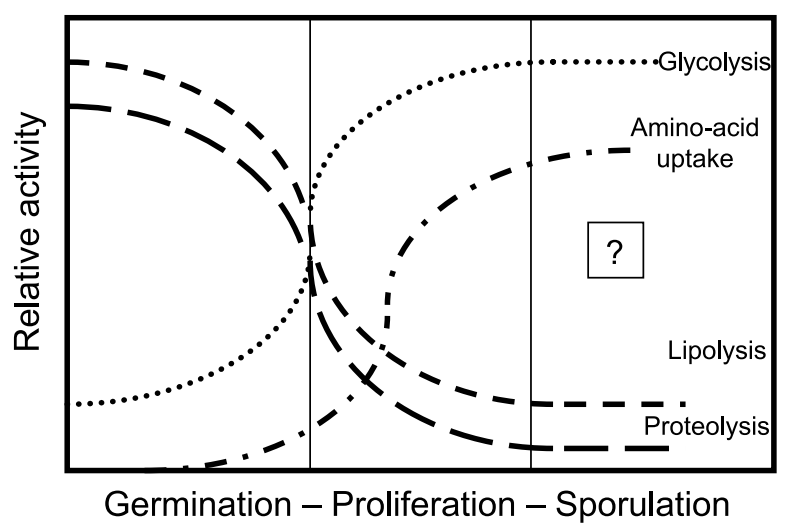

Fig. 1 Schematic diagram of fungal nutrition during infection. The relative importance of various sources of nutrient and/or energy is depicted on the $y$-axis. The $x$-axis represents a composite fungal infection arbitrarily divided into three phases: germination of the spores and penetration of the host; proliferation within the host tissue including, in some cases, the elaboration of haustoria; and the generation of spores and/or resting structures. The $x$-axis can be taken to represent both time and distance in different pathosystems.

life-cycle within the host was constructed (Fig. 1). This model can be divided into three stages.

The first stage of the fungal parasitic life-cycle is the germination of the spore and the development of structures required for host penetration. During this phase, external nutrient sources are likely to be scarce. Growth at this stage must involve the degradation of storage compounds. Genomic, histological and genetic studies all suggest that lipid catabolism is critical. There is less information relating to nitrogen reserves. Genomic studies show that many proteases are expressed, suggesting that protein turnover may be the main source of amino acids prior to penetration (Thomas et al., 2001, 2002).

The second stage, 'proliferation', occurs after penetration, where the pathogen establishes within the host and can access the nutrients within the plant tissue. Early genomic studies (Coleman et al., 1997) assumed that fungi were starving during infection. However the presence of high concentrations of hexose and amino acids during infection and the decline in ICL expression (Bowyer et al., 2000) lead us to question this assumption. The main source of energy is likely to be glycolysis. Biotrophs such as mildews, rusts and C. fulvum appear to utilize hexoses, mostly derived from sucrose, that are taken up either from the apoplast or (in the case of pathogens possessing haustoria) via haustorial membranes. Necrotrophs are also likely to take up free sugars. As they all secrete cell wall degrading enzymes, the sugars released from plant polymers would be available for absorption.

Both gene expression studies (Hahn and Mendgen, 1997) and direct measurements of mycelial bathing fluids (Solomon and Oliver, 2001) have shown that biotrophs utilize free amino acids at least as a partial nitrogen source. Some amino acids appear to be absent from the in planta environment. Enzymes synthesizing these amino acids are therefore attractive fungicide targets.

The evidence for a third stage is largely conjectural. This stage occurs late in infection where the host tissues, especially in the case of necrotrophic pathogens, are increasingly incapacitated by the pathogen. As a result, nutrients are depleted, leading to starvation of the pathogen. During this stage, the pathogen produces spores for progeny dissemination. No reports have been published on nutrient availability during this final stage of infection.

Much of our knowledge comes from a small number of pathogens that have diverse unique features. To take two examples, the $C$. fulvum-tomato interaction is confined to the apoplast whilst $U$. fabae haustoria are tough enough to be isolated intact. We must ask if these results are representative. It is clear that the most powerful way to approach these questions is genetic, by isolating and characterizing well-defined mutants strains, but that this approach is problematic for all obligate pathogens, including most biotrophs for which non-pathogenic mutants are non-viable. It is clear that more research into the genetically tractable and economically significant interactions is required.

\section{ACKNOWLEDGEMENTS}

The Grains Research and Development Corporation, Australia supports work in the authors' laboratory. We thank Dr M. Oliver for a critical review of the manuscript.

\section{REFERENCES}

van den Ackerveken, G., Dunn, R., Cozijnsen, A., Vossen, J., van den Broek, H. and de Wit, P. (1994) Nitrogen limitation induces expression of the avirulence gene avr9 in the tomato pathogen Cladosporium fulvum. Mol. Gen. Genet. 243, 277-285.

Bailey, A., Mueller, E. and Bowyer, P. (2000) Ornithine decarboxylase of Stagonospora (Septoria) nodorum is required for virulence toward wheat. J. Biol. Chem. 275, 14242-14247.

Balhadere, P.V., Foster, A.J. and Talbot, N.J. (1999) Identification of pathogenicity mutants of the rice blast fungus Magnaporthe grisea by insertional mutagenesis. Mol. Plant-Microbe Interact. 12, 129-142.

Bowyer, P., Mueller, E. and Lucas, J. (2000) Use of an isocitrate lyase promoter-GFP fusion to monitor carbon metabolism of the plant pathogen Tapesia yallundae during infection of wheat. Mol. Plant. Pathol. 1, 253-262.

Coleman, M., Henricot, B., Arnau, J. and Oliver, R.P. (1997) Starvationinduced genes of the tomato pathogen Cladosporium fulvum are also induced during growth in planta. Mol. Plant-Microbe Interact. 10, 11061109.

Cubitt, A.B., Heim, R., Adams, S.R., Boyd, A.E., Gross, L.A. and Tsien, R.Y. (1995) Understanding, improving and using green fluorescent proteins. Trends Biochem. Sci. 20, 448-455.

Cutler, S.B., Cooley, R.N. and Caten, C.E. (1998) Cloning of the nitrate reductase gene of Stagonospora (Septoria) nodorum and its use as a selectable marker for targeted transformation. Curr. Genet. 34, 128137. 
Dehne, H.W. (1982) Interaction between vesicular-arbuscular mycorrhizal and plant pathogens. Phytopath. 72, 1115-1119.

Gernns, H., von Alten, H. and Poehling, H.M. (2001) Arbuscular mycorrhiza increased the activity of a biotrophic leaf pathogen - is a compensation possible? Mycorrhiza, 11, 237-243.

Goodwin, P.H., Li, J. and Jin, S. (2000) Evidence for sulfate depression of an arylsulfatase gene of Colletotrichum gloeosporioides $\mathrm{f}$. sp. malvae during infection of round-leaved mallow, Malva pusilla. Physiol. Mol. Plant Pathol. 57, 169-176.

Hahn, M. and Mendgen, K. (1997) Characterisation of in planta-induced rust genes isolated from a haustorium-specific cDNA library. Mol. PlantMicrobe Interact. 10, 427-437.

Hahn, M., Neef, U., Struck, C., Gottfert, M. and Mendgen, K. (1997) A putative amino acid transporter is specifically expressed in haustoria of the rust fungus Uromyces fabae. Mol. Plant-Microbe Interact. 10, 438-445.

Hewitt, H.G. (1998) Fungicides in Crop Protection. Wallingford, UK: CAB International.

Hibberd, J.M., Whitbread, R. and Farrar, J.F. (1996a) Carbohydrate metabolism in source leaves of barley grown in $700 \mu \mathrm{mol} \mathrm{mol}^{-1} \mathrm{CO}_{2}$ and infected with powdery mildew. New Phytol. 133, 659-671.

Hibberd, J.M., Whitbread, R. and Farrar, J.F. (1996b) Effect of elevated concentrations of $\mathrm{CO}_{2}$ on infection of barley by Erysiphe graminis. Physiol. Mol. Plant Pathol. 48, 37-53.

Hoffland, E., Jeger, M.J. and van Beusichem., M.L. (2000) Effect of nitrogen supply rate on disease resistance in tomato depends on the pathogen. Plant Soil, 218, 239-247.

Hoffland, E., van Beusichem., M.L. and Jeger, M.J. (1999) Nitrogen availability and susceptibility of tomato leaves to Botrytis cinerea. Plant Soil, 210, 263-272.

Holliday, P. (1992) A Dictionary of Plant Pathology. Cambridge, UK: Cambridge University Press.

Huber, D.M. and Watson, R.D. (1974) Nitrogen form and plant disease. Annu. Rev. Phytopathol. 12, 139-165.

Hwang, C. and Kolattukudy, P. (1995) Isolation and characterization of genes expressed uniquely during appressorium formation by Colletotrichum gloesporoides comidia induced by the surface wax. Mol Gen. Genet. 247, 282-294.

Idnurm, A. and Howlett, B.J. (2001) Pathogenicity genes of phytopathogenic fungi. Mol. Plant Path. 2, 229-240.

Jennings, D.B., Ehrenshaft, M., Pharr, D.M. and Williamson, J.D. (1998) Roles for mannitol and mannitol dehydrogenase in active oxygen-mediated plant defense. Proc. Natl Acad. Sci. USA, 95, 1512915133.

Jennings, D.H. and Lysek, G. (1996) Fungal Biology: Understanding the Fungal Lifestyle. Oxford, UK: BIOS Scientific Publishers.

Jensen, B. and Munk, L. (1997) Nitrogen-induced changes in colony density and spore production of Erysiphe graminis f. sp. hordei on seedlings of six spring barley cultivars. Plant Pathol. 46, 191-202.

de Jong, J.C., McCormack, B.J., Smirnoff, N. and Talbot, N.J. (1997) Glycerol generates turgor pressure in rice blast. Nature, 389, 244-245.

Joosten, M.H.A.J., Hendrickx, L.J.M. and De Wit, P.J.G.M. (1990) Carbohydrate composition of apoplastic fluids isolated from tomato leaves inoculated with virulent or avirulent races of Cladosporium fulvum (syn. Fulvia fulva). Neth. J. PI. Pathol. 96, 103-112.

Kimura, A., Takano, Y., Furusawa, I. and Okuno, T. (2001) Peroxisomal metabolic function is required for appressorium-mediated plant infection by Colletotrichum lagenarium. Plant Cell, 13, 1945-1957.
Lau, G. and Hamer, J.E. (1996) Regulatory genes controlling MPG1 expression and pathogenicity in the rice blast fungus Magnaporthe grisea. Plant Cell, 8, 771-781.

Lehtinen, U. (1993) Plant cell wall degrading enzymes of Septoria nodorum. Physiol. Mol. Plant Pathol. 43, 121-134.

Long, D.H., Lee, F.N. and TeBeest, D.O. (2000) Effect of nitrogen fertilization on disease progress of rice blast on susceptible and resistant cultivars. Plant Dis. 84, 403-409.

Marmeisse, R., van den Ackerveken, G., Goosen, T., De Wit, P. and van den Broek, H. (1993) Disruption of the avirulence gene avr9 in two races of the tomato pathogen Cladosporium fulvum cause virulence on tomato genotypes with the complementary resistance gene Cf9. Mol. Plant-Microbe Interact. 6, 412-417.

Marzluf, G.A. (1997) Molecular genetics of sulfur assimilation in filamentous fungi and yeast. Annu. Rev. Microbiol. 51, 73-96.

Matsuyama, N. and Dimond, A.E. (1973) Effect of nitrogenous fertilizer on biochemical processes that could affect lesion size of rice blast. Phytopathol. 63, 1202-1203.

Mei, B., Budde, A.D. and Leong, S.A. (1993) sid1, a gene initiating siderophore biosynthesis in Ustilago maydis: Molecular characterization, regulation by iron, and role in phytopathogenicity. Proc. Natl Acad. Sci. USA, 90, 903-907.

Mendgen, K., Struck, C., Voegele, R.T. and Hahn, M. (2000) Biotrophy and rust haustoria. Physiol. Mol. Plant Pathol. 56, 141-145.

Mueller, E., Bailey, A., Corran, A., Michael, A.J. and Bowyer, P. (2001) Ornithine decarboxylase knockout in Tapesia yallundae abolishes infection plaque formation in vitro but does not reduce virulence toward wheat. Mol. Plant-Microbe Interact. 14, 1303-1311.

Murphy, J.M. and Walton, J.D. (1996) Three extracellular proteases from Cochliobolus carbonum: cloning and targeted disruption of ALP1. Mol. Plant-Microbe Interact. 4, 290-297.

Namiki, F., Matsunaga, M., Okuda, M., Inoue, I., Nishi, K., Fujita, Y. and Tsuge, T. (2001) Mutation of an arginine biosynthesis gene causes reduced pathogenicity in Fusarium oxysporum f. sp. Melonis. Mol. PlantMicrobe Interact. 4, 580-584.

Newton, A.C. and Caten, C.E. (1988) Auxotrophic mutants of Septoria nodorum isolated by direct screening and by selection for resistance to chlorate. Trans. Br. Mycol. Soc. 90, 199-207.

Noeldner, P.K.M., Coleman, M.J., Faulks, R. and Oliver, R.P. (1994) Purification and characterization of mannitol dehydrogenase from the fungal tomato pathogen Cladosporium fulvum (syn. Fulvia fulva). Physiol. Mol. Plant Pathol. 45, 281-289.

Oliver, R., Henricot, B. and Segers, G. (2000) Cladosporium fulvum, cause of leaf mould of tomato. In Fungal Pathology. (Kronstad, J., ed.), pp. 65-92. Dordrecht, Netherlands: Kluwer.

Scholes, J.D., Lee, P.J., Horton, P. and Lewis, D.H. (1994) Invertase: understanding changes in the photosynthetic and carbohydrate metabolism of barley leaves infected with powdery mildew. New Phytol. 126, 213-222.

Segers, G., Bradshaw, N., Archer, D., Blissett, K. and Oliver, R.P. (2001) Alcohol oxidase is a novel pathogenicity factor for Cladosporium fulvum, but aldehyde dehydrogenase is dispensable. Mol. Plant-Microbe Interact. 14, 367-377.

Snoeijers, S.S., Perez-Garcia, A., Joosten, M.H.A.J. and De Wit, P.G.M. (2000) The effect of nitrogen on disease development and gene expression in bacterial and fungal plant pathogens. Eur. J. Plant Path. 106, 493-506.

Sohn, J., Voegele, R.T., Mendgen, K. and Hahn, M. (2000) High 
activation of vitamin B1 biosynthesis genes in haustoria of the rust fungus Uromyces fabae. Mol. Plant-Microbe Interact. 13, 629-636.

Solomon, P.S., Nielson, P.S., Clark, A.J. and Oliver, R.P. (2000) Methionine synthase, a gene required for methionine synthesis, is expressed in planta by Cladosporium fulvum. Mol. Plant Path. 1, 315-323.

Solomon, P.S. and Oliver, R.P. (2001) The nitrogen content of the tomato leaf apoplast increases during infection by Cladosporium fulvum. Planta, 213, 241-249.

Solomon, P.S. and Oliver, R.P. (2002) Evidence that $\gamma$-aminobutyric acid is a major nitrogen source during Cladosporium fulvum infection on tomato. Planta, 214, 414-420.

Stephenson, S.A., Hatfield, J., Rusu, A.G., Maclean, D.J. and Manners, J.M. (2000) CgDN3: An essential pathogenicity gene of Colletotrichum gloeosporioides necessary to avert a hypersensitive-like response in the host. Stylosanthes Guianensis Mol. Plant-Microbe Interact. 13, 929-941.

Sutton, P.N., Henry, M.J. and Hall, J.L. (1999) Glucose, and not sucrose, is transported from wheat to wheat powdery mildew. Planta, 208, $426-430$.

Talbot, N.J. (1990) Genetic and genomic analysis of Cladosporium fulvum. PhD Thesis, University of East Anglia, UK.

Talbot, N.J., Ebbole, D.J. and Hamer, J.E. (1993) Identification and characterisation of MPG1, a gene involved in pathogenicity from rice blast fungus Magnaporthe grisea. Plant Cell, 5, 1575-1590.

Talbot, N.J., McCafferty, H.R.K., Ma, M., Moore, K. and Hamer, J.E. (1997) Nitrogen starvation of the rice blast fungus Magnaporthe grisea may act as an environmental cue for disease symptom expression. Physiol. Mol. Plant Pathol. 50, 179-195.

Thines, E., Weber, R.W.S. and Talbot, N.J. (2000) MAP kinase and protein kinase A-dependent mobilization of triacyglycerol and glycogen during appressorium turgor generation by Magnaporthe grisea. Plant Cell, 12, 1703-1718.

Thomas, S.W., Glaring, M.A., Rasmussen, S.W., Kinane, J.T. and Oliver, R.P. (2002) Transcript profiling in the barley mildew pathogen Blumeria graminis by serial analysis of gene expression (SAGE). Mol. Plant-Microbe Interact. 15, 847-856.

Thomas, S.W., Rasmussen, S.W., Glaring, M.A., Rouster, J.A., Christiansen, S.K. and Oliver, R.P. (2001) Gene identification in the obligate fungal pathogen Blumeria graminis by expressed sequence tag analysis. Fungal Genet. Biol. 33, 195-211.

Tonukari, N.J., Scott-Craig, J., S. and Walton, J.D. (2000) The Cochliobolus carbonum SNF1 gene is required for cell wall-degrading enzyme expression and virulence on maize. Plant Cell. 12, 237-247.

Voegele, R.T., Struck, C., Hahn, M. and Mendgen, K. (2001) The role of haustoria in sugar supply during infection of broad bean by the rust fungus Uromyces fabae. Proc. Natl Acad. Sci. USA, 98, 8133-8138.

Walters, D.R. (2000) Polyamines in plant-microbe interactions. Physiol. Mol. Plant Pathol. 57, 137-146.

Weber, R.W.S., Wakley, G.E., Thines, E. and Talbot, N.J. (2001) The vacuole as central element of the lytic system and sink for lipid droplets in maturing appressoria of Magnaporthe grisea. Protoplasma, 216, 101-112. 